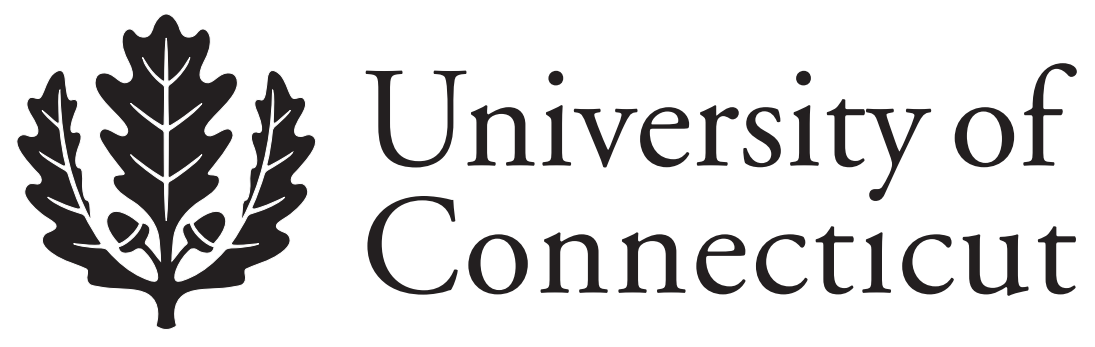

Department of Economics Working Paper Series

\title{
Is the Compensation Model for Real Estate Brokers Obsolete?
}

Thomas J. Miceli

University of Connecticut

Katherine A. Pancak

University of Connecticut

C. F. Sirmans

University of Connecticut

Working Paper 2006-23

November 2006

341 Mansfield Road, Unit 1063

Storrs, CT 06269-1063

Phone: (860) 486-3022

Fax: (860) 486-4463

http://www.econ.uconn.edu/

This working paper is indexed on RePEc, http://repec.org/ 


\begin{abstract}
This study examines the traditional compensation model for real estate brokers under which both the listing and buyer brokers are paid by the seller based on a percentage of the property sales price. We argue that this model has not evolved to reflect contemporary legal agency relationships and technology-driven information availability. It therefore creates substantial transactional inefficiencies for buyers and sellers at both the matching and bargaining stages of a transaction. While there is evidence that market forces are pushing for a change in the status quo, there is also evidence that the brokerage industry is resisting this change by pursuing anti-competitive policies and laws. We explore the economics of the current and alternative compensation structures and suggest policy implications regarding anti-competitive behavior in the brokerage industry.
\end{abstract}

Journal of Economic Literature Classification: D83, L85, R33

Keywords: agency, brokerage, multiple listings, percentage commission

We acknowledge the helpful comments of Abdullah Yavas (special issue editor), an anonymous reviewer, and participants at the Annual Meeting of the Real Estate Society, April 2006. 
Compensation Model Draft

June 8, 2006

Page 2 of 30

\section{Introduction}

In the traditional model of real estate brokerage, the seller agrees to pay the commission based on a percentage of the property sales price. The percent today is typically in the range of 5 to 6 percent. ${ }^{1}$ Cooperating brokers are invited to participate in the transaction by introducing and working with potential buyers, and the commission is then split between the listing broker and the cooperating (buyer) broker. ${ }^{2}$

A real estate broker's services can be separated into two basic functions: matching, where a real estate broker assists sellers and buyers in finding a suitable trading partner, and, once a match is made, bargaining, where a broker assists the buyer and/or seller in negotiating the terms and conditions of a purchase and sale agreement (Miceli, Pancak, and Sirmans, 2000). ${ }^{3}$ Two significant changes have occurred which make the current compensation structure obsolete. The first is a technogical change affecting the matching stage, and the second is a legal change affecting the bargaining stage.

The matching function of real estate brokers has significantly changed given the emergence of the widespread availability of information on the internet. Prior to the 1990's, real estate brokers had almost exclusive control over information about properties listed for sale and prices of properties that recently sold. For buyers and sellers to gain access to this information, they had to work with a real estate broker. In many ways, brokers were real estate market information gatekeepers, controlling information needed by buyers regarding available listings, and by sellers regarding potential buyers. While real estate brokers argue that they have copyrightable property ownership of listing information, ${ }^{4}$ information about property for sale is readily available to all consumers on the internet. Sites like realtor.com and zillow.com provide extensive detail on properties, including size and location, as well as 
photos and online tours. A buyer can now search properties and narrow down choices from the computer, rather than requiring a live tour with a broker. The traditional compensation model for brokers has not evolved to reflect their diminished role in the matching stage.

Agency relationships in real estate brokerage have also changed, affecting the bargaining stage of a brokerage transaction. Previously, the broker working with the buyer was a subagent of the seller and represented the seller's best interest. Thus it was logical that the seller would compensate the subagent. There were, however, numerous problems with subagency, not the least of which was that both the buyer and the subagent working with the buyer did not realize that the subagent owed legal duties to the seller. ${ }^{5}$ Starting in the 1990's, however, states began to revise their licensing laws, allowing for buyer brokerage and in some instances discouraging subagency. Now, in the majority of transactions, the broker working with the buyer is no longer a subagent of the seller, but rather an agent of the buyer (and referred to as a "buyer broker"). ${ }^{6}$ While a legal relationship between buyer and broker has been established (from non-representation to agency representation), the compensation model has not changed accordingly. In most transactions, the seller still pays the buyer broker's fee via the split commission. ${ }^{7}$

Economists argue that the market will take care of any inefficiencies that changing circumstances create in a compensation model. And we have in fact begun to see new brokerage models emerge to meet the changes of the last decade. There have been recent attempts by discount brokerage firms to reduce commission rates and fee-for-service firms to unbundle brokerage services and price them separately. ${ }^{8}$ For example, Foxtons charges sellers $3 \%$ of the purchase price, giving buyer brokers $1 \%$. In return, sellers must show their own property. Commentators have noted, however, that buyer brokers are not apt to show 
these listing because their compensation is smaller than for traditionally listed property. ${ }^{9}$ Insight Realty and MLS Lion allow sellers to pay a flat fee, between $\$ 300$ and $\$ 700$, to have their property listed on a local MLS, and then sellers pay a commission to the broker that locates a buyer. ${ }^{10}$ This solves the problem of attracting buyer brokers to the property. HelpU-Sell Realty offers sellers a menu of options for set fees. For $\$ 2,950$, a broker will handle all traditional listing services with the exception of home showings and open houses. A seller could contract separately for additional services. ${ }^{11}$

While the market is exploring various brokerage compensation structures, it appears that there is significant industry resistance to any such change. The Government Accountability Office (GAO) has alleged that brokers desiring to maintain the traditional compensation structure are undermining the efforts of discount and fee-for-service brokers. ${ }^{12}$ Recently, the U.S. Department of Justice (DOJ) sued the National Association of Realtors (NAR) have alleged noncompetitive behavior in NAR policies that allow brokers to restrict the display of their listing information on other websites and restrict brokers that display MLS information online from referring customers to other brokers for a fee. ${ }^{13}$ The DOJ and FTC have also commented to various states that laws restricting brokers from offering rebates, and incentives to consumers as well as laws requiring brokers to provide a minimum level of services to consumers, limit competition. ${ }^{14}$

It is time to ask whether the traditional residential real estate brokerage compensation model is obsolete. In exploring this question, we organize our paper as follows. The second section reviews prior literature on real estate brokerage compensation. The third section models the two real estate brokerage functions, matching and bargaining, focusing on the compensation structure, particularly split commissions. We argue that in the matching stage, 
split commissions tend to channel broker efforts into unproductive competition for listings rather than productive search for buyers, while in the bargaining stage, split commissions computed as a percentage of the sale price distort incentives for agents (especially those representing buyers) to negotiate in the best interests of their clients. In the fourth section, we examine the relationship between the current compensation model and alleged anticompetitive behavior in the real estate industry, hypothesizing that the reason for the behavior is to maintain the current compensation structure. Finally, the fifth section summarizes our proposals for reform of the compensation model.

\section{Prior Literature}

Numerous articles have discussed whether real estate brokerage is competitive, efficient, and equitable, taking the compensation structure as a given. Regarding competition among brokers, some studies find uniformity among rates and others find that rates vary (Sirmans and Turnbull, 1997). Whether uniformity is a result of competition or collusion, ${ }^{15}$ however, has been much discussed. Bartlett (1981) and Crockett (1992) point to cooperation among brokers as the source of uniform commissions. Braswell and Poe (1992) take this analysis one step further, positing that the practice of giving one broker an exclusive right to sell creates anti-competition.

In contrast, Yavas (2001) contends that fixed costs for brokers drive rate uniformity, while Levmore (1993) argues that fixed commissions are expected since they eliminate the problem of agents devoting excessive effort to properties where the the marginal commission is higher. Sykes (1993) disagrees with Levmore, reasoning that commissions are uniform 
because it helps in the matching of sellers and brokers, in that there is then no incentive for a broker to exaggerate sales prospects.

As for efficiency, Miceli (1992) and Crocket (1982) argue that uniform commission rates will lead to inefficient non-price competition. Yavas (1996) concludes that a net listing, as compared to a flat fee or percentage commission, maximizes both broker profit and buyer/seller surplus. Miceli (1991) reveals that commission split arrangements maximize the joint profit, but not joint effort, of brokers. Further literature, outside the scope of this article, discusses brokers' effect on price and time on the market. ${ }^{16}$

As for equitability, Rutherford, Springer, and Yavas (2005) have shown that the percentage commission structure creates an agency problem, where the agent spends too little effort. This is in keeping with most past theoretical models that have argued that, while the percentage commission structure aligns agent and seller interests, an agent will still not expend the efficient level of effort on behalf of sellers. (But see Williams (1998), who develops a model in which the percentage commission structures does not create agency problems.)

When looking at the above issues, the prior research has predominantly focused on the search by brokers for buyers, which we referred to as the matching stage. The brokerage function of assisting in negotiating, which we refer to as the bargaining state, is typically only mentioned in passing. This may be due to the historical fact that in the past both brokers involved in a transaction were theoretically negotiating on behalf of the seller. The advent of buyer brokerage, however, has changed the analysis of the bargaining stage. Now, at least theoretically, there is negotiation between the listing broker on behalf of the seller and the buyer broker on behalf of the buyer. Curran and Schrag (2000) looked at the effect of buyer 
brokerage, showing that buyer brokerage lowers buyers' search cost and improves buyers' negotiating position in the case of high end properties. However, Yavas and Colwell (1999) point out the obvious problem that when buyer brokers are paid a percentage of sales price, their interests are not aligned with those of the buyer.

Very little has been written in the academic literature proposing alternative broker compensation structures. Miceli (1991) briefly discussed an alternative arrangement with the goal of maximizing broker search effort, while still inducing them to take on listings. He proposed that sellers pay a fixed fee to a broker to list a property on the MLS, and then a commission to only the broker who locates a buyer. This is very close to some of the alternative broker arrangements we are seeing the marketplace now, a decade and half later. From the perspective of bargaining function, however, this arrangement does not address the agency problems associated with buyer brokers being compensated based on the sales price.

Colwell, Trefzger, and Treleven $(1993,1994)$ present an alternative fee structure recognizing the advent of buyer brokerage. In their residual share model, total broker compensation is preset, based on a percentage of assessed value, not sales price. The listing broker receives a percentage of this compensation, and the buyer broker receives the difference between the set compensation and the listing broker's share. This structure helps to align the interests of the seller with the listing broker and the interests of the buyer with the buyer broker. Based on this model, as the price increases, the listing broker's share of the compensation increases and the buyer broker's share decreases, and vice versa. Yavas and Colwell (1999) examine the incentives and efficiencies of the Colwell, Trefzger, and Treleven (1993) compensation model, including the addition of negative externalities. They expand the model slightly by proposing that the seller pay the listing broker's fee and the buyer pay the 
buyer broker's fee. This compensation model is interesting in that it appears to align incentives correctly. However, it does not separate out the matching and bargaining functions of brokers, which may be appropriate in today's transactional environment.

Yavas and Colwell (1999) end their article by briefly speculating that as MLS information is distributed on the internet, sellers may pay a fixed amount to list on the MLS. The seller may then hire a broker separately to assist with negotiations. The buyer would separately hire a buyer broker for property showings and to assist in negotiation. Now that property sale information is widely available, it is time to look at this proposed compensation structure more carefully.

In the next section we revisit the incentives created under the traditional compensation model and speculate as to how these incentives impact transactional efficiency and competition. Our analysis differs from previous work in several ways. First, we explicitly separate out and model both the matching and bargaining functions of a broker; second, we examine the impact of split commissions on broker search for both buyers and listings; third, we allow buyers to be represented by buyer agents and derive compensation structures for both buyer's and seller's agents that reflects their conflicting incentives; and finally, we examine the relationship between compensation structures and recently alleged anticompetitive behavior in the brokerage industry.

\section{The Traditional Compensation Model}

Elsewhere we have argued that a real estate transaction can be divided into two distinct stages: the matching stage, during which buyers and sellers search for suitable trading partners, and the bargaining stage, during which the sale price and other terms are negotiated 
(Miceli, Pancak, and Sirmans, 2000). Traditionally, brokers have played a crucial role in both stages, but these roles are quite different and potentially incompatible in the following sense. During the matching stage, cooperation among brokers in the form of shared information is important for achieving the best possible matches between buyers and sellers. Once a match is made, however, the buyer and seller (and their brokers) enter a bargaining phase that puts them in direct conflict, primarily with regard to the determination of the sale price. Thus, a climate of cooperation gives way to one of conflict. We believe that this tension between cooperation and conflict is a primary source of the problems with the brokerage industry as it is currently structured.

In the next two sub-sections, we examine the matching and bargaining stages from the perspective of broker compensation. ${ }^{17}$ In the matching stage we examine the incentive effects of split commissions in MLS sales regarding the search efforts of brokers. Then, in the bargaining stage, we derive the optimal fee structure for both buyer and seller agents, and compare them to the current practice of calculating the gross commission as a percentage of the sale price and splitting it between the buyer's and seller's brokers. We will conclude that in both stages, the current split commission compensation structure is inadequate regarding broker incentives.

\subsection{The Matching Stage}

As noted, the function of real estate brokers during the matching stage is to search for buyers on behalf of home sellers. ${ }^{18}$ The probability of a successful match during this stage is presumably an increasing function of the number of potential buyers who see a property. Thus, sellers achieve the maximum probability of success when brokers share their information widely through the MLS, for then sellers gain access to the entire stock of buyers 
Compensation Model Draft

June 8, 2006

Page 10 of 30

by contacting any single broker. In this way, the prospect for success of sellers is independent of the actual structure of the brokerage industry (the number and scale of firms), which is determined by the technology of search, as described below.

If brokers do not share listing information with other brokers, access to buyers may be limited. A broker may perceive that withholding a listing from the MLS may increase his or her chance of attracting a buyer and keeping the entire commission. This is a consequence of the standard fee arrangement in co-brokered (MLS) sales, whereby the listing broker splits his or her commission with a buyer broker. Therefore, while sharing brokerage information through the MLS is efficient, the split-commission compensation model may create a structure that impedes full sharing of information in practice. We will argue that withholding listing information from other brokers is unproductive in that it limits a seller's potential trading partners and thus decreases the likelihood of an efficient match. The allocative efficiency of the brokerage industry can be improved by ensuring that information about property for sale reaches as many potential buyers as possible.

In addition to searching for buyers, brokers also search (compete) for listings. This again is a consequence of the compensation model, which entitles the broker first contacted by a seller (the listing broker) to a share of the commission from any sale involving that listing, including those in which another broker locates the buyer. ${ }^{19}$ We will argue however, that unlike an unimpeded search for buyers, competition for listings is unproductive in that it does not increase the likelihood of a sale, but only affects the distribution of gains. The allocative efficiency of the brokerage industry can potentially be improved by discouraging such wasteful competition for listings.

To illustrate the foregoing points, consider the following model. Let 
$m=$ number of brokers;

$n_{i}=$ number of buyers located by broker $i$;

$c\left(n_{i}\right)=$ cost of search per broker, $c^{\prime}>0$;

$A=$ gross commission from a sale;

$\alpha=$ share of the commission paid to the buyer's broker in an MLS sale, $0 \leq \alpha \leq 1$;

$1-\alpha=$ share of the commission received by the listing broker in an MLS sale;

$q_{i}\left(s_{i}\right)=$ probability that broker $i$ attracts a given listing; ${ }^{20}$

$s_{i}=$ broker $i$ 's expenditure on competition for listings, where $q_{i}{ }^{\prime}>0, q_{i}{ }^{\prime \prime}<0$.

Under the traditional split commission arrangement, broker $i$ can receive revenue from three sources (Yinger, 1981). First, he can attract a listing and match it with one of his own buyers. In this case, he earns the entire commission, $A$. The expected income from this source is

$$
q_{i}\left(\frac{n_{i}}{N}\right) A,
$$

where $N \equiv \sum_{j}^{m} n_{j}$ is the total number of buyers. Thus, $n_{i} / N$ is the probability that a match is

made with one of $i$ 's buyers. Second, broker $i$ can attract a listing and match it with another broker's buyer, in which case, he earns a fraction $1-\alpha$ of the commission. The expected income from this source is

$$
q_{i}\left(\frac{N-n_{i}}{N}\right)(1-\alpha) A
$$

where $\left(N-n_{i}\right) / N$ is the probability of a match with another broker's buyer. Finally, broker $i$ can locate a buyer for another broker's listing, in which case he earns a fraction $\alpha$ of the commission. The expected income from this source is

$$
\left(1-q_{i}\right)\left(\frac{n_{i}}{N}\right) \alpha A .
$$


Finally, let $p(N)$ be the probability that a seller finds a match with one of the $N$ listings during the matching stage, where $p^{\prime}>0$. Broker $i$ 's overall expected income is therefore the sum of (1), (2) and (3), weighted by $p(N)$, or

$$
p(N) A\left\{q_{i}\left[\frac{n_{i}}{N}+\left(\frac{N-n_{i}}{N}\right)(1-\alpha)\right]+\left(1-q_{i}\right) \frac{n_{i}}{N} \alpha\right\},
$$

which, after simplifying, becomes

$$
p(N) A\left[q_{i}(1-\alpha)+\frac{n_{i}}{N} \alpha\right] .
$$

The objective of broker $i$ is to choose $n_{i}$ and $s_{i}$ to maximize expected income net of search costs:

$$
p(N) A\left[q_{i}(1-\alpha)+\frac{n_{i}}{N} \alpha\right]-c\left(n_{i}\right)-s_{i}
$$

We assume that the brokerage industry is sufficiently competitive that in maximizing (5), broker $i$ takes $A, \alpha, N$, and the behavior of other brokers as given. The resulting first-order conditions for $n_{i}$ and $s_{i}$, respectively, are

$$
\begin{aligned}
& p(N) A \frac{\alpha}{N}=c^{\prime}\left(n_{i}\right) \\
& p(N) A q_{i}{ }^{\prime}(1-\alpha)=1 .
\end{aligned}
$$

Brokers therefore search for buyers, and compete for listings, to the point where the marginal expected income equals the marginal cost. Note that $\alpha$ is crucial in determining the amount that brokers invest in the two activities. Specifically, as $\alpha$, the share of the commission paid to the buyer's broker, increases, brokers invest relatively more in search for buyers and less in competition for listings. This observation leads to the following result: 
Proposition: It is in the collective interests of brokers, and also allocatively efficient, to eliminate competition among brokers for listings by setting $\alpha=1$. That is, the broker who actually locates a buyer receives the entire commission.

Proof: To prove that eliminating competition for listings is in the collective interests of brokers, sum the expected profits in (5) across the $m$ brokers. Since $\sum_{j} q_{j}=1$ for any equilibrium vector of broker search levels, and $\sum_{j} n_{j}=N$ by definition, the term in square brackets reduces to one. Thus, given identical brokers, aggregate profits are

$$
p(m n) A-m[c(n)+w(s)],
$$

where $N=m n$. Since $q$ drops out of the expected income term, competition for listings is purely dissipative. Brokers would therefore collectively benefit by setting $\alpha=1$ in (6) and (7), or by awarding the full commission to the broker who finds a buyer. To prove allocative efficiency, set $\alpha=1$ in (6), and note that free entry of brokers implies that profits in (5) are zero, or

$$
p(N) A \frac{n}{N}-c(n)=0
$$

Combining this with (6) implies that

$$
c^{\prime}(n)=c(n) / n,
$$

or that average search costs per broker are minimized. ${ }^{21}$ Thus, the brokerage industry is efficiently organized.

The preceding analysis has shown that split commissions in MLS transactions have the undesirable effect of channeling brokers' efforts into wasteful competition for listings 
since, while "ownership" of a listing is privately valuable, it is socially unproductive. An implication is that broker hoarding of listing information in hopes of receiving the entire commission is unproductive.

We note several qualifications to the preceding conclusion. First, many have argued that split commissions are necessary for brokers to be willing to share their listings with other brokers. Thus, elimination of splits might undermine information sharing in the matching stage. While this may be true in a world where access to the MLS is exclusively controlled by participating brokers, our proposal involves eliminating ownership of the MLS by brokers and granting free access to sellers (possibly for a fixed fee to cover maintenance costs). No one broker would own a listing, but instead all participating brokers would search for a buyer under a winner-take-all fee structure.

Second, it could be argued that such an arrangement could lead to a different sort of inefficiency—namely, a wasteful race among brokers to be first to locate a buyer. ${ }^{22}$ This did not happen in the current model because we assumed that the industry was large enough that individual brokers took $N$ (and hence $p(N)$ ) as given. However, if the number of brokers is small enough that they perceive their effect on $p(N)$, such a race could emerge.

Third, the model is based on the premise that searching for buyers is the only productive activity of brokers. This reflects the idea that the demand for brokerage services is derived from sellers, so there is no need for brokers to "search" for them. This is especially relevant as the technology of search permits more and more sellers to search on their own, thus reducing the need for brokers in the matching stage.

Finally, nothing in the current analysis required the compensation of brokers to be based on a percentage of the sale price. A broker only needs an incentive to bring together 
suitable trading partners, not necessarily to obtain the highest price for the seller or the lowest price for the buyer. As such, at the matching stage, the broker acts more as a middleman than as a representative. In some states, licensing laws will need to be rethought to allow this type of involvement.

\subsection{The Bargaining Stage}

Once a buyer is found, the matching stage ends and the bargaining stage begins. It is here that the actual sale price is determined. ${ }^{23}$ In traditional brokerage, the two stages are linked by the commission, which to this point we have treated as a constant, $A$. In fact, the commission is traditionally specified as a percentage of the sale price, or $A=\sigma P$, where $\sigma$ is the commission rate, $0<\sigma<1$, and $P$ is the negotiated price. ${ }^{24}$ A common justification for the use of a percentage commission is that it gives brokers an incentive to work hard on behalf of sellers to obtain the highest price possible (see, e.g., Zorn and Larsen, 1986). The problem, however, is that this creates perverse incentives for brokers working on behalf of buyers.

Historically, buyer brokers were viewed by the law as agents of the seller, but as discussed above, this has changed significantly in recent years due to the misperception that it often created for buyers—namely, that the buyer's broker was acting on the buyer's behalf. The use of a percentage commission as the form of compensation for brokers contributed to this conflict because, although buyer brokers typically work very closely with buyers during the matching stage, once the bargaining stage begins, their interests become aligned with the seller through the percentage commission since a higher sale price increases their compensation. Thus, regardless of what the law says, a percentage commission is fundamentally inconsistent with good advocacy for buyers during the bargaining stage in cobrokered sales. 
In view of this conflict, we derive the characteristics of an efficient compensation scheme for both buyer and seller brokers (agents) during the bargaining stage. In doing so, we assume that each party hires their own agent and therefore can structure the compensation scheme independently so as to achieve the proper incentives. ${ }^{25}$

First, we define $P\left(e_{s}, e_{b}\right)$ to be the negotiated sale price, where $e_{s}$ is the effort of the seller's agent, and $e_{b}$ is the effort of the buyer's agent (both specified in dollar terms). Thus, $P_{1}>0$ and $P_{2}<0$ (where subscripts denote partial derivatives). Next, we specify the following linear compensation schemes for the seller's agent and the buyer's agent, respectively:

$$
\begin{aligned}
& f_{s}=\beta+\gamma P \\
& f_{b}=\delta+\varepsilon P .
\end{aligned}
$$

The problem for the seller is to choose $\beta$ and $\gamma$ to maximize $P-f_{s}$, while the problem for the buyer is to choose $\delta$ and $\varepsilon$ to minimize $P+f_{b}$, in both cases subject to the incentive compatibility and participation constraints of the agents. Incentive compatibility requires that the seller's agent choose $e_{s}$ to maximize $f_{s}-e_{s}$, and the buyer's agent choose $e_{b}$ to maximize $f_{b}-e_{b}$. It immediately follows that to align the incentives of the parties perfectly, we must have $\gamma=1$ and $\varepsilon=-1$, with $\beta$ and $\delta$ being constants (i.e., independent of $P$ ). To verify this, note that when $\gamma=1$ and $\varepsilon=-1$, the agents choose $e_{s}$ and $e_{b}$, respectively, to solve

$$
\begin{aligned}
& P_{1}-1=0 \\
& -P_{2}-1=0,
\end{aligned}
$$

which define the first-best levels of effort. The optimal values of $\beta$ and $\delta$ are then set to ensure that the agent's are willing to participate in the contract.

Under this scheme, the seller's fee takes the form $\beta+P$, which has the following implications. First, the agent's return increases dollar-for-dollar with $P$, in contrast to a 
percentage commission, which increases at a much slower rate given $\sigma<1$. Thus, while the incentives of a percentage commission are in the right direction for the seller's agent, they are not very "powerful." Second, note that $\beta$ must be negative; in effect, the optimal fee has the form of a net listing, where the agent "guarantees" a fixed price to the seller, $\beta$, and then keeps the difference between this price and the actual sale price. (Essentially, the agent "buys" the house up front.) While net listings are apparently illegal for brokers, our results suggest that sellers should be allowed to negotiate them with their agents in the bargaining stage. (A possible reason that they may not choose to do so, even if allowed, is that net listings allocate all of the risk associated with price uncertainty to the agent, which would only be optimal if agents are risk neutral. $)^{26}$

Now consider the optimal fee for the buyer's agent, which takes the form $\delta-P$. In this case, the agent again effectively guarantees a price, $\delta$, and is then paid the difference between this price and the actual price. Thus, in contrast to the seller's agent's compensation, the buyer's agent's compensation increases dollar-for-dollar as the negotiated price falls. ${ }^{27}$

Note that the total compensation for two agents is given by $f_{s}+f_{b}=\beta+\delta$, where, recall, $\beta<0$. Thus, in order for this amount to be positive, we must have $\delta>-\beta$. Presumably, the market will ensure that this is the case. ${ }^{28}$ As an example, let $\delta=\$ 102,500,-\beta=\$ 97,500$, and suppose the house sells for $\$ 100,500$. Then the seller's agent's compensation is $\$ 100,500-\$ 97,500=\$ 3,000$, while the buyer's agent's compensation is $\$ 102,500-\$ 100,500=\$ 2,000 .^{29}$

An important drawback of this scheme is that, although the gross commission is positive by construction, there is no guarantee that the actual commission for both agents will be positive. In the above example, if the sale price exceeds $\$ 102,500$, the buyer's agent 
actually has to pay the buyer something, whereas if the sale price is less than $\$ 97,500$, the seller's agent has to pay the seller something. This is probably the greatest obstacle to the proposed scheme. The traditional percentage commission does not have this problem because the gross commission is computed based on the actual sale price, and is then divided according to some pre-set formula, thereby ensuring a positive payment to both agents. In conclusion, we note that the analysis in this section has not necessarily been intended as a proposal for an alternative compensation structure, especially given the problems just noted. Rather, our primary intent was to illustrate the extent to which the existing structure deviates from the optimum, especially regarding the interests of buyers.

\section{Compensation and Anti-Competitive Behavior}

The GAO has alleged that traditional brokers are resistant to nontraditional brokerage

practices. ${ }^{30}$ In fact, behavior and policies aimed at maintaining traditional practices have prompted allegations of anti-competition from the FTC and DOJ. In this section we suggest that some of the alleged anti-competitive behavior can be traced to the current compensation model.

Under the current compensation structure, we showed that, while ownership of a listing may be privately valuable for brokers, it creates an economically inefficient competition among brokers for listings. There is currently no socially productive reason for brokers to be given the right to compensation just for holding a listing. In the past, giving brokers a property right in listings may have been necessary to encourage them to seek and then share listing information with other brokers. However, given today's technology, listing information can be readily shared and accessed in a central online database. Further, listing 
broker control of listing information interferes with socially productive search for buyers. These conclusions have several implications regarding competition policy.

First, the NAR has established a policy that allows brokers to restrict the display of their listing information on other broker websites. ${ }^{31}$ At the matching stage, however, it is in the best interest of a seller to have the listing broker advertise the property as widely as possible, casting a broad net for potential buyers. In an effort to maximize his or her own income, however, a listing broker may be hesitant to share listing information, trying instead to represent both the seller and the buyer in the same transaction. ${ }^{32}$

Second, the NAR has established a policy that restricts brokers who display MLS information online from referring buyers to other brokers for a fee. It would appear that such referrals would be valuable, but if not, brokers have the option of not entering into referral arrangements. What is the rationale for discouraging this practice if the internet is involved? Traditional brokerage firms are concerned that real estate internet sites will be more successful than local real estate companies in aggregating real estate listing data and thus attracting buyers. ${ }^{33}$ The internet sites (assuming they are licensed) earn a fee by referring buyers to local brokers in return for a share of the commission from any sale. Again, in an attempt to maximize their income, listing brokers are hesitant to share listing information in this way.

Third, various states have enacted laws that restrict brokers from offering rebates and other incentives to consumers. As a result, buyer brokers are not allowed to refund a portion of their fee to buyers. Why would the brokerage industry want to disallow this practice? Again, the answer can be found in the current compensation model. Listing brokers do not want competition from real estate internet sites or buyer brokers who will use a share of the 
listing commission to encourage buyers to enter into relationships with them at the expense of the listing broker. Further, traditional listing brokers do not want competition from discount listing brokers using a rebate scheme to lower seller commission rates.

Finally, our recognition that brokerage can be divided into the matching and bargaining stage supports the idea that brokers should be able to offer different services for different fees to consumers. In fact, we have shown that the optimal compensation schemes in the matching and bargaining stages are separable, thereby allowing division of services in these stages. Dividing up brokerage compensation for services rendered, however, may not be the most profitable compensation structure for brokers, which may explain why so many states have enacted or are contemplating enacting laws requiring brokers to provide a minimum level of services to consumers. A compensation model that allows the parties to freely contract for desired services is needed.

\section{Summary of Proposals}

The current residential real estate brokerage compensation model is obsolete in that it is no longer in the best economic interests of buyers and sellers. Market forces pushing for more efficient compensation alternatives have been hampered by brokerage industry efforts to artificially maintain the status quo by pursuing various anti-competitive policies and laws. Our results suggest several changes that we now summarize.

- Recognize that brokers provide two distinct functions to consumers: matching and bargaining.

- At the matching stage, eliminate wasteful competition for listings and distorted listing broker incentives to control the pool of buyers by granting the sole claim to matching compensation to the broker who finds a ready and willing buyer. In 
effect, this involves eliminating property rights in, or ownership of, listings by brokers.

- Allow access to the MLS, or other centralized property database, by all sellers without obligating them to enter into an agency relationship with a broker. Instead, sellers may be charged a fixed fee to enter the MLS, and compensation would then be awarded exclusively to the broker who actually locates a buyer, while no compensation would be due if the seller locates a buyer on his or her own.

- At the bargaining stage, allow buyers and sellers to hire their own agents, and according to compensation schemes that are not necessarily computed as a percentage of the sale price (including net listings).

- Recognize that current alleged industry anti-competitive behavior may be an attempt to prop up a compensation scheme that, while possibly in the best interests of industry participants, is socially unproductive. 


\section{Notes}

1. United States Government Accountability Office (2005), 9-10.

2. Sharing of listing information between brokers historically began to occur at the turn of the twentieth century, as brokers were encouraging sellers to enter into exclusive rather than open listing contracts. It was not until the 1970's however, that exclusive listing became prevalent and most brokerage firms shared information and agreed to split commissions with cooperating brokers through a multiple listing system. See Edward L. Slumber, Attorney Explains MLS - Realtor Multiple Listing Service is Discussed Industry Overview", Real Estate Weekly (April 9, 2003).

3. Information on services provided is outlined in the National Association of REALTORS®, Inc. online article entitled "Why Use a REALTOR?®”. As part of what we refer to as the matching effort, a listing broker will typically provide the following services for a seller: provide information on market conditions that would effect pricing the property, list the property on an MLS, hold broker and public open houses, place hard copy and internet advertisements, and prescreen and accompany buyers seeing the property (unless there is a buyer broker, who would then do this). On the bargaining side, a listing broker would assist a seller in evaluating potential offers and negotiating an agreement, as well as seeing the agreement through to closing of title.

On the buyer's side, a buyer broker will assist in matching a buyer with a property by helping the buyer determine what they can afford, searching for property for sale, providing information about properties for sale, and showing properties. On the bargaining side, a buyer broker assists a buyer in making an offer, negotiating an 
agreement, advising as to reports and inspections on the property that should be obtained, and explaining financing options, and seeing the transaction through to closing. http://www.realtor.com/Basics/AllAbout/Realtors/Why.asp?poe=realtor , accessed 02/03/06.

4. See Blanche Evans, "DOJ Doesn't Have a Case Says MLS Attorney”, Realty News (March 14, 2006).

5. Federal Trade Commission (1983), 69.

6. See Pancak, Miceli, and Sirmans (1997).

7. We recognize that, in theory, the buyer ultimately pays the buyer broker fee in the form a higher selling price. We also note that some buyer brokerage agreements now provide that the buyer most pay a fee if the broker can not secure a commission split from the listing broker.

8. The U.S. Government Accountability Office reports that non-traditional approaches to account for only a small share of the brokerage market. United States Government Accountability Office (2005), 5.

9. Hagerty, James R. "Foxtons Redefines Its Discount Approach: New Chief Executive Raises Sales Commission to 3\%, Boosts Services and Staff." Wall Street Journal. October 27, 2004, p. B. 4.

10. Insight Realty website: http://www.insight-realty.com . MLS Lion website: http://www.mlslion.com .

11. Johansen, Erin. “Help-U-Sell Gains Converts.” Denver Business Journal, April 30, 2004. Also see Help-U-Sell website at http://www2.helpusell.com/RealtyConsultantsCT/Sellers/SaveMoney.aspx . 
12. United States Government Accountability Office (2005), 13-14.

13. United States of America v. National Association of Realtors; complaint filed September 8, 2005 in the United States District Court for the Northern District of Illinois Eastern Division. See Department of Justice website for case filings at http://www.usdoj.gov/atr/cases/nar.htm .

14. DOJ antitrust comments can be found at http://www.usdoj.gov/atr/public/comments/comments.htm . FTC antitrust comments can be found at http://www.ftc.gov/opp/workshops/comprealestate/index.htm .

15. This practice was found to be in violation of the Sherman Act in 1950 in U.S. v. National Association of Real Estate Boards, et al., 339 U.S. 485 (1950).

16. For more on these topics, and an excellent overview of the brokerage literature in general, see Benjamin, Jud and Sirmans (2000).

17. Yavas (1992) also considers these stages in a model that focuses on the search of buyers and sellers.

18. See Yinger (1981) for a formal search model of broker behavior.

19. See Bartlett (1981), Frew (1987), and Miceli (1991).

20. This can also be interpreted as the total number of listings attracted by broker $i$.

21. This conclusion is in consistent with Crockett (1982) and Miceli (1992), who show that when brokers engage in non-price competition, they do not minimize average costs.

22. See, for example, Mortensen (1982) and Lueck (1994).

23. Yavas, Miceli, and Sirmans (2001) conduct an experimental analysis of the impact of brokers on the outcome of bargaining between buyers and sellers. 
24. As noted above, since the matching and bargaining stages are sequential in time, backwards induction requires that brokers in the matching stage rationally anticipate the outcome of the bargaining stage when choosing their search strategies. Thus, the model in the previous section implicitly assumed that $A$ was independent of broker search, which may not be realistic in the case of a percentage commission.

25. Many of the results in this section have already been established, or anticipated, in previous literature. See Anglin (1994), Yavas (1996), and Colwell, Trefzger, and Treleven $(1993,1994)$.

26. For other arguments against net listings, see Anglin (1994) and Yavas (1996).

27. This scheme resembles that proposed by Colwell, Trefzger, and Treleven $(1993,1994)$, but differs in that compensation falls dollar-for-dollar with the sale price. In contrast, in their scheme, compensation falls in proportion to $c / 2$, where $c$ is the commission rate.

28. For example, the market might dictate that the gross compensation will be 5\%-6\% of the market value of the house, in which case $\beta$ and $\delta$ will be functions of the market value.

29. The values of $\beta$ and $\delta$ could be tied to the assessed value of the property, $V$, as follows. (Our approach follows Colwell, Trefzger, and Treleven, 1993, 1994.) Let $V=\$ 100,000$, and suppose the gross commission is set at $5 \%$ of this value, or $\$ 5,000$. Then, assuming an equal division of this "provisional commission," we have $\delta=(\$ 100,000)(1+.025)=\$ 102,500$, and $-\beta=(\$ 100,000)(1-.025)=\$ 97,500$. The actual commission, of course, may not be divided equally, as illustrated by the example in the text.

30. United States Government Accountability Office (2005). 
31. Under the NAR Virtual Office Website (VOW) and Internet Listing Display (ILD) policies, allows brokers to "opt out" of displaying property listed with them on a competitor's website, claiming an ownership right in listings. See NAR press release, “Justice Sues Over Wrong Policy” September 9, 2005 at http://www.realtor.org/PublicAffairsWeb.nsf/pages/narsuedoverwrongpolicy .

32. Resultant dual agency and designated agency has many agency conflicts, not directly related to this study.

33. Cendant Real Estate Services Division (2003). 


\section{References}

Anglin, P. (1994). "Contracts for the Sale of Residential Real Estate," Journal of Real Estate Finance and Economics 8, 195-211.

Bartlett, R. (1981). "Property Rights and the Pricing of Real Estate Brokerage," The Journal of Industrial Economics 30, 79-94.

Benjamin, J. D., G. D. Jud, and G. S. Sirmans. (2000). "What Do We know About Real Estate Brokerage?" Journal of Real Estate Research 20, 1-30

Braswell, M. K., and S. L. Poe. (1992). "The Residential Real Estate Brokerage Industry: A Proposal for Reform," American Business Law Journal 30, 271-334.

Cendant Real Estate Services Division. (2003). The Emerging Issues Posed By The Misues of Virtual Office Websites: The Potential Downside of VOWS, White Paper.

Colwell, P. F., J. W. Trefzger, and R. A. Trevelen. (1993). "Compensating Buyer Brokers," Illinois Real Estate Letter Winter/Spring.

Colwell, P. F., J. W. Trefzger, and R. A. Trevelen. (1994). "Residual Share Contracts for Compensating Buyer Brokers," Real Estate Review 24, 82-87.

Crockett, J. H. (1982). "Competition and Efficiency in Transacting: The Case of Residential Real Estate Brokerage," Journal of American Real Estate and Urban Economics Association 10, 209 - 227.

Curran, C., and J. Schrag. (2000). "Does it Matter Whom an Agent Serves? Evidence from Recent Changes in Real Estate Agency Law," Journal of Law and Economics 43, 265284.

Federal Trade Commission. (1983). The Residential Real Estate Brokerage Industry, Washington, D.C.: U.S. Government Printing Office.

Frew, J. (1987). "Mutiple Listing Service Participation in the Real Estate Brokerage Industry," Journal of Urban Economics 21, 272-286.

Hahn, R. W., R. E. Litan, and J. Gurman. (2005). Bringing More Competition to Real Estate Brokerage, Washington, D.C.: AEI-Brookings Joint Center for Regulatory Studies.

Levmore, S. (1993). "Commissions and Conflicts in Agency Arrangements: Lawyers, Real Estate Brokers, Underwriters, and Other Agents' Rewards," Journal of Law and Economics 36, 503-539.

Lueck, D. (1994). "Common Property as an Egalitarian Share Contract," Journal of Economic Behavior and Organization 25, 93-108. 
Miceli, T. J. (1991). "The Multiple Listing Service, Commission Splits, and Broker Effort," Journal of the American Real Estate and Urban Economics Association 19, 548-567.

Miceli, T. J. "The Welfare Effects of Non-price Competition Among Real Estate Brokers." Real Estate Economics 20, 519-532.

Miceli, T. J., K. A. Pancak, and C.F. Sirmans. (2000). "Restructuring Agency Relationships in the Real Estate Brokerage Industry: An Economic Analysis," Journal of Real Estate Research 20, 31-47.

Mortensen, D. (1982). "Property Rights in Mating, Racing, and Related Games," American Economic Review 72, 968-979.

Pancak, K. A., T. J. Miceli, and C.F. Sirmans. (1997). "Real Estate Agency Reform: Meeting the Needs of Buyers, Sellers, and Brokers," Real Estate Law Journal 25, 345-377.

Rutherford, R.C., T. M. Springer, and A. Yavas. (2005). "Conflicts Between Principals and Agents: Evidence from Residential Brokerage," Journal of Financial Economics 76, 627-665.

Sykes, A. O. (1993). "Some Thoughts on the Real Estate Puzzle: Comments on Levmore, "Commissions and Conflicts in Agency Arrangements: Lawyers, Real Estate Brokers, Underwriters, and Other Agents' Rewards," Journal of Law and Economics 36, 541-551.

United States Government Accountability Office. (2005). Real Estate Brokerage: Factors That May Affect Price Competition, Washington, D.C.

Williams, J. T. (1998). “Agency and Brokerage of Real Assets in Competitive Equilibrium,” The Review of Financial Studies 11, 239-280.

Yavas, A. (2001). "Impossibility of Competitive Equilibrium in the Real Estate Brokerage Industry," The Journal of Real Estate Research 21, 187 - 201.

Yavas, A. (1996). "Matching of Buyers and Sellers by Brokers: A Comparison of Alternative Commission Structures," Real Estate Economics 24, 97-113.

Yavas, A., and P. Colwell. (1999). "Buyer Brokerage: Incentive and Efficiency Implications," Journal of Real Estate Finance and Economics 18, 259-277.

Yavas, A., T. J. Miceli, and C.F. Sirmans. (2001). "An Experimental Analysis of the Impact of Intermediaries on the Outcome of Bargaining Games," Real Estate Economics 29, 251-276.

Yinger, J. (1981). "A Search Model of Real Estate Broker Behavior," American Economic Review 71, 591-604. 
Zorn, T., and J. Larsen. (1986). "The Incentive Effects of Flat-Fee and Percentage Commissions for Real Estate Brokers," Journal of the American Real Estate and Urban Economics Association 14, 24-47. 